\section{Estado nutricional de vitaminas A e D em crianças participantes de programa de suplementação alimentar}

\author{
Vitamin A and D status among child participants in \\ a food supplementation program
}

\author{
Concentraciones séricas de vitaminas $A$ y $D$ en \\ niños del programa de distribución de leche \\ fortificada
}

Aline Yukari Kurihayashi 1

Rosangela Aparecida Augusto 1

Fernanda Martins Dias Escaldelai 1

Lígia Araújo Martini 1

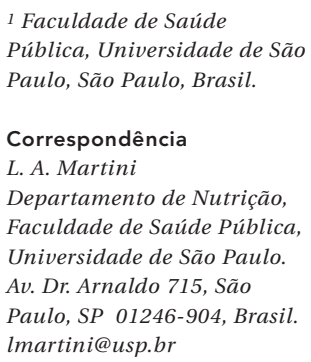

\begin{abstract}
Vitamin A and D serum concentrations and risk factors for their deficiencies were investigated in children participating in a government-sponsored fortified milk program. The study used multivariate linear regression analysis with hierarchical selection of independent variables: socio-demographic conditions, children's health, food consumption, breastfeeding, fortified milk, exposure to sunlight, anthropometric measurements, and serum concentration of retinol and 25(OH)D. Vitamin A and vitamin D insufficiency and deficiency values were defined as < $1.05 \mu \mathrm{mol} / \mathrm{L},<0.7 \mu \mathrm{mol} / \mathrm{L},<30 \mathrm{ng} / \mathrm{mL}$, and $<20 \mathrm{ng} /$ $m L$, respectively. Vitamin A and D intake was inadequate. Prevalence rates for vitamin $A$ and vitamin D insufficiency and deficiency were 19\%, $6 \%, 82 \%$, and 58\%, respectively. Factors associated with low serum vitamin A were exclusive breastfeeding for less than 120 days, low maternal schooling, maternal unemployment, more consumers offortified milk in the family, and low serum vitamin D. Factors associated with vitamin $D$ deficiency were low exposure to sunlight and low serum vitamin A. Nutritional education is needed to improve children's nutritional status.

Fortified Food; Avitaminosis; Supplementary Feeding; Nutritional Status; Government Programs
\end{abstract}

\section{Resumo}

Foram avaliados as concentrações séricas de vitaminas A e D e os fatores associados em crianças beneficiárias de programa de distribuição de leite fortificado, sendo utilizados modelos de regressão linear múltiplos com seleção hierárquica de variáveis independentes (condição sociodemográfica, de saúde, alimentação, amamentação, consumo do leite fortificado, exposição solar, antropometria, retinol e calcidiol séricos). Foram consideradas insuficiência e deficiência de vitamina A e de vitamina $D$ as concentrações séricas $<1,05 \mu \mathrm{mol} / \mathrm{L}$, 0,70 $\mathrm{mo} / \mathrm{L}$, 30ng/mL e 20ng/mL, respectivamente. Houve inadequação do consumo alimentar de vitaminas A e D. As prevalências de insuficiência e deficiência de vitamina $A$ e de vitamina $D$ foram $19 \%, 6 \%, 82 \%$ e 58\%, respectivamente. Os fatores associados às menores concentrações séricas de vitamina A foram: amamentação materna exclusiva < 120 dias, ausência de trabalho materno combinada com menor escolaridade materna, maior número de pessoas que consomem leite fortificado no domicílio e menor vitamina $D$ sérica. Para a vitamina D, foram: menor exposição ao sol e menor vitamina A sérica. Ações de educação nutricional são necessárias para melhorar a situação nutricional dessas crianças.

Alimentos Fortificados; Deficiência de Vitaminas; Suplementação Alimentar; Estado Nutricional; Programas Governamentais 


\section{Introdução}

No Brasil, apesar dos avanços obtidos nas últimas décadas com ações de combate a problemas nutricionais, as deficiências de vitaminas persistem no grupo infantil 1, a magnitude e as consequências dessas inadequações são ainda preocupantes 2,3,4,5.

A Organização Mundial da Saúde (OMS) 6 estima que, no mundo, aproximadamente, $33,3 \%$ das crianças menores de cinco anos (190 milhões) apresentam deficiência de vitamina A (retinol sérico $<0.70 \mu \mathrm{mol} / \mathrm{L}$ ). Quanto à vitamina $\mathrm{D}$, estima-se que a deficiência global [calcidiol ou $25(\mathrm{OH}) \mathrm{D}$ sérico $<20 \mathrm{ng} / \mathrm{mL}$ ou $50 \mathrm{nmol} / \mathrm{L}$ ] esteja em torno de $50 \%$ da população 4 , sendo estimado que mais de 1 bilhão de indivíduos apresentem insuficiência de vitamina D (calcidiol sérico $<30 \mathrm{ng} / \mathrm{mL}$ ou $75 \mathrm{nmol} / \mathrm{L}$ ) ou deficiência da vitamina D (calcidiol sérico $<20 \mathrm{ng} / \mathrm{mL}$ ou $50 \mathrm{nmol} / \mathrm{L}) 3$.

No Brasil, a última Pesquisa Nacional de Demografia e Saúde (PNDS 2006) 7 identificou que $17,4 \%$ de crianças menores de cinco anos estavam com deficiência de vitamina A. Quanto à situação nutricional de vitamina $\mathrm{D}$, entre os poucos dados disponíveis na literatura nacional, estudo de base populacional, realizado com crianças menores de 10 anos residentes na Região Norte do país 8 , identificou cerca de $30 \%$ de insuficiência de vitamina $\mathrm{D}(<30 \mathrm{ng} / \mathrm{mL}$ ou $75 \mathrm{nmol} / \mathrm{L})$, e, na Região Sul, estudo realizado com crianças de baixa estatura ${ }^{9}$ encontrou $60 \%$ de insuficiência de vitamina $\mathrm{D}$, sendo que $96 \%$ delas não atingiam a ingestão diária recomenda da vitamina D (200UI/dia) 10 .

Concentrações inadequadas de vitamina A prejudicam a função visual e intensificam a gravidade de processos infecciosos 11,12. A principal causa da deficiência de vitamina A está relacionada à dieta cronicamente insuficiente em vitamina A, que pode levar a baixos estoques corporais e a falhas em atender as necessidades fisiológicas 6,13,14,15, além disso, outros fatores têm sido tratados, na literatura, como possíveis preditores das concentrações séricas de vitamina A, como as condições socioeconômicas e ambientais $16,17,18,119$, características maternas 20 , peso ao nascer 21 e indicadores antropométricos 17,22. Porém, essas associações ainda são controversas na literatura 23,24 .

A principal fonte de vitamina $\mathrm{D}$ é a síntese cutânea ${ }^{3}$, por meio da exposição solar, tendo a dieta uma contribuição inferior a $10 \%$ para a biodisponibilidade dessa vitamina 25 .

No entanto, mesmo em países ensolarados, prevalências consideráveis de hipovitaminose $\mathrm{D}$ em crianças e adolescentes têm sido divul- gadas 26,27 . Esse fato pode ocorrer devido a mudanças nos hábitos de vida e a fatores ambientais como menor exposição à luz solar, utilização de filtro solar, nível de poluição, tempo de permanência em local de trabalho e de estudo maiores índices de obesidade e ainda fatores genéticos que podem influenciar o metabolismo da vitamina D 28,29,30.

A vitamina $\mathrm{D}$ tem um importante papel no metabolismo ósseo, promovendo absorção de cálcio, essencial para o desenvolvimento normal dos ossos e dentes. Assim, a deficiência de vitamina $\mathrm{D}$, além de prejudicar o crescimento infantil 2, tem, como consequência mais grave, o raquitismo 2,31 , porém níveis moderados de insuficiência também podem ter efeitos importantes na saúde ao longo da vida adulta ${ }^{32}$. Estudos têm encontrado ainda associação entre a inadequação de 25(OH)D com o aumento do risco de doenças crônicas, incluindo a doença cardiovascular 33,34, diabetes tipo 135 e tipo 2 36,37, câncer 38 e doenças autoimunes 39 .

A identificação de fatores de risco modificáveis relacionados à inadequação das concentrações séricas dessas vitaminas é importante para direcionar ações mais efetivas na prevenção dessas deficiências 40 .

As principais ações de alimentação e nutrição voltadas para a prevenção e o controle de deficiências nutricionais são a modificação e a diversificação dietética, a fortificação de alimentos e a suplementação medicamentosa 6 .

Nesse contexto, desde 1999, o Estado de São Paulo, Brasil, executa política pública de suplementação alimentar baseada na distribuição de leite fortificado, com 7,5mg de ferro, 2000UI de vitamina A e 400UI de vitamina D por litro, denominado Projeto Estadual do Leite - Vivaleite 41,42, objetivando melhorar as condições nutricionais de crianças e idosos de baixa renda. Tal projeto emprega um recurso anual de R\$ 150 milhões, com cobertura estimada de $60 \%$ de todas as famílias de baixa renda do Estado de São Paulo.

Essa política pública já teve sua efetividade avaliada apenas para a situação nutricional de ferro 43 e do crescimento infantil 44 . Porém, nenhum estudo foi realizado, até o presente momento, para a investigação da situação nutricional das vitaminas A e D nessas crianças.

Assim, diante da importância do estado nutricional de vitaminas A e D para a saúde infantil, julgou-se relevante avaliar a adequação dos indicadores biológicos das vitaminas A e D em crianças beneficiárias de programa de suplementação alimentar, residentes na região central da cidade de São Paulo, e investigar os possíveis fatores associados às concentrações séricas dessas vitaminas. 


\section{Métodos}

Estudo transversal com crianças de 2 a 7 anos de idade, beneficiárias de programa de distribuição de leite fortificado.

Para a seleção da população de estudo, realizou-se, em 2011, contato com a Secretaria Estadual de Agricultura e Abastecimento, na ocasião responsável pelo projeto, para autorização do estudo e obtenção das informações sobre os locais de distribuição do leite na cidade de São Paulo.

Os distritos foram selecionados por conveniência, levando-se, em consideração, o menor tempo para o transporte das amostras de sangue para centrifugação; dessa forma, foram selecionadas as instituições localizadas nos distritos de Bela Vista, Liberdade, República, Santa Cecília e Sé, totalizando oito entidades, dessas, quatro aceitaram participar.

Posteriormente, as famílias cadastradas foram convidadas a participar de reunião com a equipe de pesquisa para o esclarecimento dos objetivos e métodos a serem empregados na pesquisa, foram consideradas, como critérios de inclusão, crianças de ambos os sexos, residentes na cidade de São Paulo e beneficiárias do Projeto Estadual do Leite, e de exclusão: presença de febre, relato de inflamação e utilização de medicamentos anti-inflamatórios no dia da coleta e presença de alguma patologia que possa influenciar o estado nutricional, principalmente das concentrações séricas das vitaminas A e D. Participaram do estudo 84 crianças.

A coleta de dados, realizada entre dezembro de 2012 a julho de 2013, incluiu os seguintes questionários: dados socioeconômicos (escolaridade da mãe/responsável, idade materna, estado civil da mãe, número de moradores na casa, número de filhos vivos e presença de trabalho materno); saúde da criança (ocorrência de internações nos últimos 12 meses, morbidades nos últimos 15 dias, consumo atual de suplementos, duração do aleitamento materno exclusivo, a data de nascimento, o peso e o comprimento ao nascer); consumo do leite fortificado (tempo de participação no projeto, consumo ou não do leite fortificado pela criança, consumo do leite fortificado por outros moradores). Além disso, foi avaliado o consumo alimentar com a realização de dois recordatórios alimentares de 24 horas (R24h), respeitando o intervalo de, pelo menos, três dias entre os dois questionários. Foram utilizadas fotos de utensílios para facilitar o entendimento pelo entrevistado.

Foram utilizados, como referencial para a adequação de ingestão das vitaminas A e D, os valores da necessidade média estimada (EAR) $45,46,47,48$, sendo o consumo de vitamina A consi- derado adequado $\geq 210 \mu \mathrm{g} /$ dia para crianças de 1 a 3 anos e $\geq 275 \mu \mathrm{g} /$ dia para crianças de 4 a 8 anos; para o consumo de vitamina $\mathrm{D}$, valores $\geq 10 \mu \mathrm{g}$ / dia para todas as idades, os dados de consumo foram processados no software The Food Processor Visco 10.9 (Esha Research Salem, Salem, Estados Unidos).

A avaliação antropométrica foi realizada pelas medidas de peso e estatura (obtidas em duplicata), utilizando procedimentos padronizados 49 . O peso foi obtido utilizando-se balança portátil com especificidade de 100g (Tanita Corp., Arlington Heights, Estados Unidos), e, para a estatura, foi utilizado estadiômetro portátil com especificidade de 0,1cm (Seca, São Paulo, Brasil). Os indivíduos foram posicionados no centro do equipamento, utilizando somente roupas leves e sem adornos. Foram considerados baixa estatura/idade valores $<-2$ escore $\mathrm{z}$, risco de baixa estatura valores $<-1$ e excesso de peso e obesidade valores de índice de massa corporal (IMC)/idade $>1$ e $>2$ escore $\mathrm{z}$, respectivamente 50,51 .

A condição favorável à síntese cutânea de vitamina D foi avaliada pela criação de um escore, desenvolvido pelo somatório dos valores atribuídos às respostas das informações de interesse, as quais foram selecionadas com base em referencial teórico 2,3,4,5, constantes na Tabela 1 , variando de 0 (menos favorável) a 14 pontos (mais favorável).

A coleta de sangue foi realizada por uma enfermeira, devidamente treinada, no próprio domicílio da criança. A amostra de sangue obtida (10mL) foi acondicionada em tubos de ensaio seco para a obtenção do soro, com proteção à luz. Após a coleta, as amostras de sangue foram acondicionadas em caixas térmicas, com temperatura entre $2^{\circ} \mathrm{C}$ e $8^{\circ} \mathrm{C}$, e transportadas ao laboratório do Departamento de Nutrição, Faculdade de Saúde Pública, Universidade de São Paulo (FSP/ USP), no período de duas horas, onde o sangue foi centrifugado a 3 mil rotações por minuto, e as alíquotas de sangue foram separadas em microtubos e congeladas a $-80^{\circ} \mathrm{C}$ até a realização das análises bioquímicas. As alíquotas de soro $(1,5 \mathrm{~mL})$ destinadas à determinação do retinol sérico foram mantidas em microtubo âmbar.

As análises das concentrações séricas das vitaminas A e D foram realizadas pela técnica de cromatografia líquida de alta eficiência (highperformance liquid chromatography - HPLC), utilizando-se kit específico (Chromsystems Instruments \& Chemicals $\mathrm{GmbH}$, Munique, Alemanha), coeficiente de variação intraensaio $1,9 \%$ e interensaio de $2,8 \%$, sendo considerados como insuficiente em vitamina A concentrações séricas $\leq 1,05 \mu \mathrm{mol} / \mathrm{L}$ e deficientes valores $\leq 0,70 \mu \mathrm{mol} / \mathrm{L} 52$. Para a vitamina $\mathrm{D}$, foram con- 
Tabela 1

\begin{tabular}{|c|c|}
\hline Variáveis/Possíveis respostas & Valor \\
\hline \multicolumn{2}{|c|}{ Mãe leva a criança para atividade ao ar livre? } \\
\hline Não & 0 \\
\hline Sim & 1 \\
\hline \multicolumn{2}{|l|}{ Horário desse passeio? } \\
\hline Manhã & 0 \\
\hline Tarde & 1 \\
\hline \multicolumn{2}{|l|}{ Frequência que realiza o passeio? } \\
\hline Número de vezes/semana & $0-7$ \\
\hline \multicolumn{2}{|l|}{ Utiliza proteção quando exposta ao sol? } \\
\hline Sim & 0 \\
\hline Não & 1 \\
\hline \multicolumn{2}{|l|}{ Qual(is) tipo(s) de proteção utilizado(s)? } \\
\hline Protetor solar e/ou mais de um tipo & 0 \\
\hline Boné/Chapéu & 1 \\
\hline Não utiliza & 2 \\
\hline \multicolumn{2}{|l|}{ Cor da criança? } \\
\hline Negra & 0 \\
\hline Não branca & 1 \\
\hline Branca & 2 \\
\hline Escore (mínimo e máximo) & $0-14$ \\
\hline
\end{tabular}

siderados como insuficiência valores $\leq 30 \mathrm{ng} /$ $\mathrm{mL}(75 \mathrm{nmol} / \mathrm{L})$ e deficiência valores $\leq 20 \mathrm{ng} / \mathrm{mL}$ (50nmol/L) 3 .

As características gerais das crianças foram descritas por distribuição de frequências simples, as concentrações séricas das vitaminas foram descritas por valores medianos e seus respectivos intervalos interquartis $\left(\mathrm{IQ}_{1-3}\right)$.

As avaliações dos fatores associados ao retinol e ao calcidiol séricos foram feitas por meio de regressão linear múltipla, ajustada para idade, com seleção hierárquica de variáveis. Para investigação dos preditores das concentrações séricas de cada vitamina, foram testadas, em cada nível hierárquico, as seguintes variáveis:

Nível distal (condição socioeconômica e demográfica): sexo da criança, escolaridade materna, presença de trabalho materno, número de moradores na casa, número de irmãos na casa e condição marital.

Nível intermediário (variáveis relacionadas aos cuidados com a criança): aleitamento materno, desmame, idade da mãe/responsável, número de moradores que consomem o leite fortificado no domicílio, tempo de permanência no projeto.

Nível proximal (estado nutricional, condição de saúde e consumo alimentar): estatura/idade e IMC/idade, morbidade recente, uso de suplementos, consumo alimentar de vitamina A (para o modelo de vitamina A), consumo alimentar de vitamina $\mathrm{D}$ (para o modelo de vitamina $\mathrm{D}$ ), concentração sérica de vitamina D (para o modelo de vitamina A), concentração sérica de retinol (para o modelo de vitamina D). O escore de condição favorável à síntese cutânea de vitamina D (que incluía as informações de exposição solar e cor da pele) foi incluído nesse nível para o modelo de vitamina D. Para a modelagem, inicialmente, realizou-se análise de regressão entre a variável resposta e cada uma das variáveis independentes a fim de selecionar as variáveis que entrariam no modelo $(p<0,20)$. Após essa seleção, iniciou-se a inclusão das variáveis (selecionadas na etapa anterior) de seu respectivo nível, seguindo a sequência de cada nível. Nessa etapa, permaneceram, na análise, as variáveis que obtiveram $\mathrm{p}<0.10$ Adotou-se, como nível de significância estatística, $\mathrm{p}<0,05$.

No nível distal, após serem testadas a variável escolaridade materna ( $<5$ anos; $\geq 5$ anos) e trabalho materno (sim, não) individualmente, optou-se por testar também a combinação entre essas variáveis a fim de ver o efeito combinado dessas características, resultando em 4 categorias: 0 " $\geq 5$ anos de estudo e mãe trabalha" (melhor situação); 1 " $<5$ anos de estudo e mãe trabalha"; 2 " $\geq 5$ anos de estudo e mãe não trabalha" 3 " $<5$ anos de estudo e mãe não trabalha" (pior situação).

Foram feitas comparações segundo faixa etária (2-3 anos e 4-7 anos) para os seguintes parâmetros: concentrações séricas e o consumo dietético das vitaminas A e $\mathrm{D}$, consumo diário do leite fortificado e consumo de outro tipo de leite, utilizando o teste de Wilcoxon, devido à ausência de normalidade dos desfechos. Para melhor compreensão, foram apresentados, para cada faixa etária, as medianas e os respectivos intervalos interquartis $\left(\mathrm{IQ}_{1-3}\right)$ dos desfechos.

Os dados foram processados utilizando-se o software Stata versão 10 (Stata Corp., College Station, Estados Unidos).

O estudo seguiu os preceitos éticos estabelecidos na Resolução no 196/96 do Conselho Nacional de Saúde, que regulamenta pesquisas envolvendo seres humanos, sendo aprovado pelo Comitê de Ética da FSP/USP (protocolo no 2309/2012).

\section{Resultados}

A Tabela 2 apresenta as características gerais das crianças estudadas e a distribuição dos valores medianos das concentrações séricas das vitami- 
nas A e D, segundo características das crianças. Observa-se que as crianças estavam distribuídas igualmente segundo sexo e faixa etária, com média de idade de quatro anos ( $D P=1$ ), e que a ocorrência de crianças não brancas e que receberam leite materno exclusivo por mais de quatro meses era um pouco maior na amostra. A prevalência de baixo peso ao nascer foi de $6 \%$, porém há de se considerar que quatro em cada dez crianças não dispunham dessa informação anotada no cartão de saúde. A maioria das crianças frequentava escola ou creche, não apresentava episódio recente de morbidade, não usava suplemento vitamínico e estava há mais de um ano no programa. Quanto à exposição solar, apesar de a maioria das crianças $(75 \%)$ se expor ao sol, essa prática era realizada com baixa frequência, em média, duas vezes na semana ( $\mathrm{DP}=2$ ), e ainda cerca de $40 \%$ utilizavam proteção solar.

Em relação às características familiares, a maior parcela das mães/responsáveis tinha mais de 30 anos, possuía mais de cinco anos de estudo, trabalhava, não possuía companheiro e tinha, em média, três filhos (DP $=2)$. A ocorrência de diluição intrafamiliar do leite fortificado esteve presente em quase todas as famílias (Tabela 2).

Referente ao peso e à altura, uma a cada quatro crianças apresentava excesso de peso, a inadequação do consumo de vitamina A e D esteve presente em cerca de $24 \%$ e $100 \%$ das crianças, respectivamente (Tabela 2). A maioria das crian- ças apresentava inadequação das concentrações séricas de vitamina D, e uma a cada cinco crianças apresentava insuficiência de vitamina A e/ou risco de déficit de estatura.

As concentrações séricas de vitaminas A e D (Tabela 3), bem como do consumo dessas vitaminas não diferiram segundo grupo etário, somente o volume consumido de outros leites foi superior no grupo de menor idade. Para a vitamina D, o valor sérico mediano $(17,8 \mathrm{ng} / \mathrm{mL})$ mostra-se abaixo do valor de adequação proposto $(\geq 30 \mathrm{ng} / \mathrm{mL})$, ao contrário do que se observou no valor da concentração sérica de vitamina A $(1,5 \mu \mathrm{mol} / \mathrm{L})$ que se manteve adequado em relação ao valor proposto $(\geq 1,05 \mu \mathrm{mol} / \mathrm{L})$. Quanto à ingestão de vitaminas, foram observados baixo consumo para a vitamina $\mathrm{D}$ e valores altos para o consumo da vitamina A, sendo que os alimentos que mais contribuíram para a vitamina A foram ingestão de vísceras bovina e de aves.

As médias das concentrações séricas para vitamina A e D foram: $1,7 \mu \mathrm{mol} / \mathrm{L}(\mathrm{DP}=0,8 \mu \mathrm{mol} / \mathrm{L})$ e $19,9 \mathrm{ng} / \mathrm{mL}$ (DP $=12,0 \mathrm{ng} / \mathrm{mL}$ ).

Os fatores associados às menores concentrações séricas de retinol (Tabela 4) foram: menor escolaridade materna combinada com ausência de trabalho materno, menor duração da amamentação exclusiva (< 120 dias), maior número de pessoas que consomem o leite fortificado no domicílio e menor concentração sérica de vitamina D.

\begin{tabular}{|c|c|c|c|}
\hline \multirow[t]{2}{*}{ Variável } & \multirow[t]{2}{*}{ n (\%) } & Vitamina A ( $\mu \mathrm{mol} / \mathrm{L})$ & \multirow{2}{*}{$\begin{array}{c}\text { Vitamina D (ng/mL) } \\
\text { Mediana }\left(\mathrm{IQ}_{1-3}\right)\end{array}$} \\
\hline & & Mediana $\left(I Q_{1-3}\right)$ & \\
\hline \multicolumn{4}{|l|}{ Sexo } \\
\hline Masculino & $37(44,0)$ & $1,59(1,16 ; 2,50)$ & $16,7(11,70 ; 27,20)$ \\
\hline Feminino & $47(56,0)$ & $1,53(1,14 ; 1,95)$ & $18,0(10,50 ; 24,80)$ \\
\hline \multicolumn{4}{|l|}{ Cor da criança } \\
\hline Branca & $35(41,7)$ & $1,47(1,05 ; 1,95)$ & $16,40(11,70 ; 27,2)$ \\
\hline Não branca & $49(58,3)$ & $1,60(1,20 ; 2,43)$ & $18,60(11,30 ; 24,90)$ \\
\hline \multicolumn{4}{|c|}{ Frequenta escola/creche } \\
\hline $\operatorname{Sim}$ & $78(92,8)$ & $1,52(1,14 ; 2,00)$ & $17,40(11,30 ; 26,90)$ \\
\hline Não & $6(7,1)$ & $1,97(1,81-2,42)$ & $20,50(11,70 ; 23,20)$ \\
\hline \multicolumn{4}{|c|}{ Idade da criança (anos) } \\
\hline $2--\mid 3$ & $37(44,0)$ & $1,60(1,23 ; 2,42)$ & $17,10(11,70 ; 26,90)$ \\
\hline $4--17$ & $47(55,9)$ & $1,53(0,85 ; 2,00)$ & $18,00(10,50 ; 24,90)$ \\
\hline
\end{tabular}

(continua) 
Tabela 2 (continuação)

\begin{tabular}{|c|c|c|c|}
\hline Variável & $\mathrm{n}(\%)$ & $\begin{array}{c}\text { Vitamina A }(\mu \mathrm{mol} / \mathrm{L}) \\
\text { Mediana }\left(\mathrm{IQ}_{1-3}\right)\end{array}$ & $\begin{array}{c}\text { Vitamina } D(\mathrm{ng} / \mathrm{mL}) \\
\text { Mediana }\left(\mathrm{IQ}_{1-3}\right)\end{array}$ \\
\hline \multicolumn{4}{|l|}{ Peso ao nascer (gramas) } \\
\hline$<2.500$ & $5(5,9)$ & $1,75(1,16 ; 1,89)$ & $22,30(18,50 ; 24,90)$ \\
\hline$\geq 2.500$ & $45(53,6)$ & $1,60(1,22 ; 2,00)$ & $14,50(10,40 ; 22,50)$ \\
\hline Não sabe & $34(40,5)$ & $1,49(1,14 ; 2,42)$ & $19,20(14,10 ; 30,90)$ \\
\hline \multicolumn{4}{|l|}{ Duração da amamentação (dias) } \\
\hline$<120$ & $32(38,1)$ & $1,23(0,95 ; 1,75)$ * & $2,90(2,38 ; 3,17)$ \\
\hline$\geq 120$ & $52(61,9)$ & $1,73(1,22 ; 2,50)$ & $2,74(2,41 ; 3,25)$ \\
\hline \multicolumn{4}{|l|}{ Uso de suplemento vitamínico } \\
\hline Sim & $12(14,6)$ & $1,52(1,14 ; 2,00)$ & $18,25(11,70 ; 27,20)$ \\
\hline Não & $70(85,3)$ & $1,66(1,25 ; 2,17)$ & $14,90(12,35 ; 22,45)$ \\
\hline Não sabe & $2(1,9)$ & $2,25(2,00 ; 2,50)$ & $15,70(11,30 ; 20,10)$ \\
\hline Presença de episódio recente de morbidade & $19(22,6)$ & $1,50(0,93 ; 2,72)$ & $16,00(10,40 ; 21,90)$ \\
\hline \multicolumn{4}{|l|}{ Ocorrência de diluição intrafamiliar } \\
\hline Não & $7(8,3)$ & $2,24(1,40 ; 2,54)$ & $16,00(11,70 ; 17,30)$ \\
\hline Sim & $77(91,7)$ & $1,52(1,15 ; 2,00)$ & $18,50(11,30 ; 26,90)$ \\
\hline \multicolumn{4}{|l|}{ Idade da mãe/responsável (anos) } \\
\hline $21 \mid-30$ & $17(20,0)$ & $1,30(1,14 ; 2,20)$ & $19,40(16,70 ; 24,90)$ \\
\hline $30 \mid-60$ & $67(80,0)$ & $1,78(1,33 ; 2,24)$ & $16,00(10,50 ; 23,20)$ \\
\hline \multicolumn{4}{|l|}{ Escolaridade da mãe/responsável (anos) } \\
\hline$<5$ & $33(29,3)$ & $1,38(1,10 ; 1,95) * \star$ & $16,70(10,50 ; 26,90)$ \\
\hline$\geq 5$ & $51(60,7)$ & $1,54(1,16 ; 2,20)$ & $19,70(13,10 ; 29,10)$ \\
\hline \multicolumn{4}{|l|}{ Mãe trabalha } \\
\hline Não & $41(48,8)$ & $1,27(0,93 ; 1,95) * \star$ & $2,91(2,31 ; 3,21)$ \\
\hline Sim & $43(51.2)$ & $1,78(1,35 ; 2,20)$ * & $2,83(2,58 ; 3,29)$ \\
\hline \multicolumn{4}{|l|}{ Situação marital } \\
\hline Com companheiro & $29(34,5)$ & $1,38(0,96 ; 1,95)$ & $16,40(10,50 ; 21,90)$ \\
\hline Sem companheiro & $55(65,5)$ & $1,59(1,22 ; 2,20)$ & $18,50(12,90 ; 28,60)$ \\
\hline \multicolumn{4}{|l|}{ Moradores na casa (número de pessoas) } \\
\hline$<4$ & $25(29,8)$ & $1,81(1,38 ; 2,24)$ & $17,30(11,70 ; 22,30)$ \\
\hline$\geq 4$ & $59(70,2)$ & $1,40(1,10 ; 2,00)$ & $18,50(11,30 ; 28,30)$ \\
\hline \multicolumn{4}{|l|}{ Uso de proteção quando exposto ao sol } \\
\hline Não & $36(42,9)$ & $1,37(1,03 ; 1,99)$ & $18,75(13,60 ; 27,35)$ \\
\hline Sim & $27(32,1)$ & $1,70(1,16 ; 2,20)$ & $17,10(10,40 ; 28,60)$ \\
\hline Não se expõe ao sol & $21(25,0)$ & $1,60(1,30 ; 2,20)$ & $15,30(10,00 ; 20,30)$ \\
\hline \multicolumn{4}{|l|}{ Estado nutricional } \\
\hline Inadequação de vitamina $A(<1,05 \mu \mathrm{mol} / \mathrm{L})$ & $16(19,0)$ & $0,78(0,65 ; 0,89)$ & $9,65(6,55 ; 14,80)$ \\
\hline Deficiência de vitamina $A(<0,70 \mu \mathrm{mol} / \mathrm{L})$ & $5(6,0)$ & $0,46(0,35 ; 0,62)$ & $5,90(5,20 ; 8,20)$ \\
\hline Inadequação de vitamina $\mathrm{D}(<30 \mathrm{ng} / \mathrm{mL})$ & $69(82,1)$ & $1,40(1,12 ; 1,95)$ & $15,50(10,40 ; 20,30)$ \\
\hline Deficiência de vitamina $D(<20 \mathrm{ng} / \mathrm{mL})$ & $49(58,3)$ & $1,33(0,96 ; 1,85)$ & $13,10(8,40 ; 16,40)$ \\
\hline Estatura/idade $<-2$ escore $z$ & $3(3,6)$ & $1,76(0,78 ; 2,00)$ & $3,00(2,31 ; 3,47)$ \\
\hline Estatura/idade $<-1$ escore $z$ & $16(19,0)$ & $1,34(1,05 ; 1,82)$ & $18,55(13,55 ; 23,60)$ \\
\hline $\mathrm{IMC} /$ altura $>1$ escore $\mathrm{z}$ & $22(26,2)$ & $1,69(1,35 ; 1,95)$ & $3,00(2,31 ; 3,47)$ \\
\hline $\mathrm{IMC} /$ altura $>2$ escore $z$ & $6(7,2)$ & $1,66(1,52 ; 2,50)$ & $2,57(2,00 ; 3,47)$ \\
\hline \multicolumn{4}{|l|}{ Inadequação do consumo } \\
\hline Vitamina A & $20(23,8)$ & $1,80(1,05 ; 2,46)$ & $19,20(12,30 ; 24,85)$ \\
\hline Vitamina D & $84(100,0)$ & $1,53(1,15 ; 2,07)$ & $17,75(11,50 ; 25,90)$ \\
\hline
\end{tabular}

IMC: índice de massa corporal.

$* p<0,005$.

${ }^{* *} p<0,20$ (obtido da regressão linear).

Nota: alguns $\mathrm{n}$ diferem devido à ausência de valores em algumas variáveis. 
Tabela 3

Mediana e intervalo interquartil - $1 Q_{1-3}$ dos valores séricos, do consumo alimentar de vitamina $A$ e $D$ e do consumo do leite

fortificado e de outros leites, segundo faixa etária.

\begin{tabular}{|c|c|c|c|}
\hline \multirow[t]{3}{*}{ Vitamina } & \multicolumn{3}{|c|}{ Faixa etária (anos) } \\
\hline & $2-3(n=37)$ & $4-7(n=47)$ & Total $(\mathrm{N}=84)$ \\
\hline & Mediana $\left(\mathrm{IQ}_{1-3}\right)$ & Mediana $\left(\mathrm{IQ}_{1-3}\right)$ & Mediana $\left(\mathrm{IQ}_{1-3}\right)$ \\
\hline A sérica $(\mu \mathrm{mol} / L)$ & $1,6(1,2 ; 2,4)$ & $1,5(0,8 ; 2,0)$ & $1,5(1,1 ; 2,0)$ \\
\hline$D$ sérica $(\mathrm{ng} / \mathrm{mL})$ & $17,1(11,7 ; 26,9)$ & $18,0(10,5 ; 24,9)$ & $17,8(11,5 ; 25,9)$ \\
\hline A dieta (ug/dia) & $384,6(284,1 ; 571,5)$ & $311,2(216,9 ; 441,8)$ & $354,2(255,7 ; 535,8)$ \\
\hline D dieta (ug/dia) & $2,5(2,3 ; 3,7)$ & $2,4(1,9 ; 3,7)$ & $2,5(2,0 ; 3,7)$ \\
\hline Vivaleite (mL/dia) & $200,0(120 ; 300)$ & $180,0(100 ; 240)$ & $200(100 ; 270)$ \\
\hline Outro leite (mL/dia) * & $130,0(5 ; 245)$ & $90,0(0 ; 175)$ & $100(100 ; 200)$ \\
\hline
\end{tabular}

* $p<0,005$.

\section{Tabela 4}

Fatores associados ao estado nutricional de retinol * (ajustado para idade), obtidos por regressão linear múltipla, modelo hierárquico. São Paulo, Brasil, 2013.

\begin{tabular}{|c|c|c|c|c|c|c|}
\hline \multirow[t]{2}{*}{ Variável } & \multicolumn{3}{|c|}{ Bruto } & \multicolumn{3}{|c|}{ Ajustado } \\
\hline & \multicolumn{2}{|c|}{$\beta(\mathrm{IC} 95 \%)$} & \multirow[t]{2}{*}{ Valor de p } & \multicolumn{2}{|c|}{$\beta(\mathrm{IC} 95 \%)$} & \multirow[t]{2}{*}{ Valor de $p$} \\
\hline \multicolumn{5}{|l|}{ Nível distal } & & \\
\hline \multicolumn{7}{|l|}{ Combinação escolaridade } \\
\hline \multicolumn{7}{|l|}{ (anos) e trabalho materno } \\
\hline$\geq 5$ e mãe trabalha & Referência & & & Referência & & \\
\hline$<5$ e mãe trabalha & 0,006 & $(-0,189 ; 0,201)$ & 0,951 & 0,006 & $(-0,189 ; 0,201)$ & 0,951 \\
\hline$\geq 5$ e mãe não trabalha & $-0,092$ & $(-0,260 ; 0,076)$ & 0,279 & $-0,092$ & $(-0,260 ; 0,076)$ & 0,279 \\
\hline$<5$ e mãe não trabalha & $-0,195$ & $(-0,367 ;-0,024)$ & 0,026 & $-0,195$ & $(-0,367 ;-0,024)$ & 0,026 \\
\hline \multicolumn{7}{|l|}{ Nível intermediário } \\
\hline $\begin{array}{l}\text { Quantidade de pessoas que } \\
\text { consomem o leite fortificado }\end{array}$ & $-0,029$ & $(-0,051 ;-0,006)$ & 0,013 & $-0,025$ & $(-0,050 ; 0,001)$ & 0,043 \\
\hline \multicolumn{7}{|l|}{$\begin{array}{l}\text { Amamentação materna } \\
\text { exclusiva (dias) }\end{array}$} \\
\hline$\leq 120$ & Referência & & & Referência & & \\
\hline$\geq 121$ & 0,268 & $(0,147 ; 0,387)$ & 0,000 & 0,257 & $(0,133 ; 0,382)$ & 0,000 \\
\hline \multicolumn{7}{|l|}{ Nível proximal } \\
\hline Calcidiol sérico (ng/mL) & 0,011 & $(0,006 ; 0,016)$ & 0,000 & 0,011 & $(0,007 ; 0,015)$ & 0,000 \\
\hline
\end{tabular}

* Retinol ( $\mu \mathrm{mol} / \mathrm{L})$ em unidade de raiz quadrada.

Menores concentrações séricas de vitamina D (Tabela 5) foram associadas a menores valores do escore de condição favorável à síntese cutânea de vitamina $\mathrm{D}$ e à menor concentração sérica de retinol.

\section{Discussão}

Importantes inadequações nos indicadores biológicos das vitaminas A e D e também na ingestão dessas vitaminas foram identificadas nas crianças atendidas pelo programa. A ocorrência de inadequação de vitamina $\mathrm{A}(<1,05 \mu \mathrm{mol} / \mathrm{L})$ ocorreu em uma a cada cinco crianças e, para a vitamina D, 8 a cada 10 crianças apresentaram 
Fatores associados ao estado nutricional de calcidiol * (ajustado para idade), obtidos por regressão linear múltipla, modelo hierárquico. São Paulo, Brasil, 2013.

\begin{tabular}{|c|c|c|c|c|c|c|}
\hline \multirow[t]{2}{*}{ Variável } & \multicolumn{3}{|c|}{ Bruto } & \multicolumn{3}{|c|}{ Ajustado } \\
\hline & \multicolumn{2}{|c|}{$\beta(\mathrm{IC} 95 \%)$} & $\begin{array}{l}\text { Valor } \\
\text { de } p\end{array}$ & \multicolumn{2}{|r|}{$\beta(\mathrm{IC} 95 \%)$} & $\begin{array}{l}\text { Valor } \\
\text { de } p\end{array}$ \\
\hline \multicolumn{7}{|l|}{ Nível proximal } \\
\hline Escore de condição favorável para síntese cutânea ** & 0,036 & $(-0,012 ; 0,084)$ & 0,146 & 0,046 & $(0,003 ; 0,088)$ & 0,035 \\
\hline Retinol sérico $(\mu \mathrm{mol} / \mathrm{L})$ & 0,363 & $(0,212 ; 0,510)$ & 0,000 & 0,377 & $(0,232 ; 0,522)$ & 0,000 \\
\hline
\end{tabular}

* Calcidiol ( $\mathrm{ng} / \mathrm{mL}$ ) em unidade logarítimica;

** Considerou, além da exposição solar, a cor da pele da criança.

insuficiência e 5 a cada 10 crianças, deficiência. Estes dados indicam que possivelmente a presença de diversos fatores, além da utilização do alimento fortificado, contribuíram para esse desfecho e sinalizam a necessidade de reavaliação da conduta de fortificação.

Nas últimas décadas, um cenário favorável vem sendo estabelecido no Brasil, marcado por grandes mudanças na situação econômica, com sucessivas transformações nos determinantes sociais das doenças e melhoria da organização dos serviços de saúde 53. Políticas públicas de saúde e nutrição estão sendo direcionadas para a redução da deficiência da vitamina A, apoiadas na suplementação com megadoses de vitamina A e na fortificação de alimentos, como é o caso de São Paulo com o projeto Vivaleite. No entanto, apesar das melhorias alcançadas, nossos resultados indicam que ainda persistem prevalências de hipovitaminose A em crianças.

Cabe lembrar que, no início da década de 1990, o Brasil juntamente com os países membros das Nações Unidas foram signatários de diversos compromissos internacionais, em que metas específicas foram acordadas sobre as deficiências de micronutrientes a serem alcançadas até o ano 2000. Entre as metas, constava a eliminação completa da deficiência de vitamina A 54 .

Comparando a deficiência de vitamina A das crianças do programa de suplementação (6\%) com as estimativas nacionais $(17,4 \%) 7$ e da Região Sudeste (20\%) 7, verificamos que a situação nutricional das crianças estudadas apresenta-se melhor, com isso, podemos aventar a hipótese de que o programa possa ter efeito positivo no estado nutricional de vitamina $\mathrm{A}$, mesmo diante da prática comum das famílias de diluírem o produto recebido entre os demais moradores da casa.

Quanto à vitamina $\mathrm{D}$, a situação nutricional das crianças estudadas é mais preocupante que a de muitos países de alta e também de baixa renda 2,4, como os Estados Unidos (50\% de inadequação em crianças de 1 a 5 anos), Nova Zelândia (média 50nmol/L; IC95\%: 45-54) 2,55, México (24\% de deficiência e $30 \%$ de insuficiência) 56 , Mongólia (média de 41nmol/L; DP = 3,33) 2,55.

Adicionalmente, as deficiências das vitaminas A e D estiveram associadas entre si, agravando o risco nutricional dessas crianças, uma vez que carências combinadas resultam em maior suscetibilidade a doenças e prejuízos importantes para o crescimento e desenvolvimento das crianças 57. Especula-se que tais deficiências combinadas sejam consequência da condição socioeconômica das crianças avaliadas, em que não apenas a ausência de alimentos fonte de vitaminas, mas as condições de moradia e hábitos de vida contribuíram para esse achado.

Apesar de não dispormos de uma avaliação das crianças ao ingressarem no programa, destaca-se que não houve associação entre o estado nutricional dessas vitaminas e a variável "tempo de permanecia no programa de suplementação alimentar". Uma possível explicação é que, apesar de essas crianças receberem um alimento fortificado, que supre $70 \%$ da RDA (recommended dietary allowances - ingestão dietéticas recomendada) para vitamina A quando consumido adequadamente $(500 \mathrm{~mL})$, provavelmente a alta ocorrência de diluição intrafamiliar minimiza o potencial do leite fortificado em melhorar a condição nutricional de vitamina A dessas crianças. Essa situação foi verificada no modelo final de regressão para vitamina $\mathrm{A}$, pois quanto maior o número de pessoas que consumiam o leite fortificado no domicílio, menor eram as concentrações séricas de vitamina A das crianças.

Outro importante fator de risco identificado foi a diferença significativa entre as concentrações séricas de vitamina A de filhos de "mães que 
não trabalhavam e possuíam menor escolaridade" com as de filhos de "mães que trabalhavam e possuíam maior escolaridade”. Inúmeras pesquisas têm mostrado que existe uma forte relação entre a melhor condição socioeconômica, como a educação materna, e a saúde da criança, propiciando melhores cuidados preventivos (higiene, imunizações e alimentação) e curativos (manejo doméstico das doenças e busca precoce do atendimento) 58,59,60.

Por outro lado, maior concentração sérica de retinol foi associada com maior tempo de aleitamento materno exclusivo ( $\geq 120$ dias). Isso pode ser entendido pelo fato de que a introdução precoce de alimentos complementares, além de estar relacionada à menor aporte de nutrientes importantes, aumenta a vulnerabilidade da criança a diarreias, infecções, o que resultará em um comprometimento do estado nutricional 6 .

Dentre os fatores de risco associados à baixa concentração sérica de vitamina $\mathrm{D}$, identificouse que a exposição solar foi o principal determinante dessa condição. O escore criado para este estudo mede simultaneamente diversas características que interferem na síntese cutânea da vitamina, como a cor da pele, a exposição solar, horário, frequência e tipo de proteção utilizada. Nesse contexto, os menores escores de condição favorável à síntese de vitamina $\mathrm{D}$ foram associados à insuficiência dessa vitamina. Não foi identificada nenhuma associação com o consumo do leite fortificado e o consumo de vitamina D. Portanto, os resultados encontrados estão de acordo com a literatura 2,3,4,5, mostrando que a combinação da falta de exposição solar ou exposição com baixa frequência e uso de proteção solar, principalmente em pessoas de pele não branca, estão entre os principais fatores associados a menores concentrações séricas de vitamina D.

É bem estabelecido que mudanças do estilo de vida e dos fatores ambientais, com consequente diminuição da exposição solar, são os principais fatores causais da inadequação do indicador biológico de vitamina D. A utilização de protetor solar, essencial para a prevenção de câncer de pele, funciona como barreira para a absorção de radiação UV-B, estando demonstrado que um fator de proteção 15 reduz, em 99\%, a capacidade de síntese dessa vitamina 61 . Além disso, indivíduos de pele escura necessitam de 3 a 5 vezes mais tempo de exposição para uma produção semelhante de vitamina $\mathrm{D}$ à de um indivíduo de pele clara 62 .

De fato, a exposição solar é baixa, mesmo em países com latitude favorável, principalmente nas áreas urbanas, devido à falta de ambientes com iluminação natural 62,63, situação muito comum nas residências de quase a totalidade das famílias estudadas, além do fato de residirem no centro da cidade de São Paulo, onde a poluição também pode ser um dos fatores que influenciaram nos resultados finais, pois interfere na incidência do raios solares 62

Com relação à quantidade consumida do alimento fortificado em questão, observa-se que esse leite contém 400UI/L de vitamina D, e que o consumo mediano das crianças é de $200 \mathrm{~mL} /$ dia, isso equivale ao atendimento de $20 \%$ das necessidades diárias de vitamina D. Nos Estados Unidos, todas as fórmulas para lactentes devem conter obrigatoriamente de 40 a 100UI de vitamina D por $100 \mathrm{kcal}$ ou, pelo menos, $400 \mathrm{UI}$ de vitamina $\mathrm{D} / \mathrm{L} 30$, ou seja, a mesma quantidade presente no Vivaleite. No entanto, o efeito dessas quantidades é questionado por pesquisadores 30 , pois o raquitismo continua sendo relatado nesse país. Muitos especialistas concordam que, na ausência de exposição solar adequada, é necessário 800-1.000UI de vitamina D por dia para crianças de todas as idades e adultos de todas as idades 64,65 , embora essa ainda não seja uma recomendação das organizações governamentais ou pediátricas.

Nossos resultados levam a diversos questionamentos sobre a ausência de efetividade da fortificação do Vivaleite com a vitamina D, incluindo a possível inadequação da quantidade adicionada, independente da prática comum de diluição intrafamiliar, a falta de controle laboratorial da quantidade de vitamina D presente no leite fortificado, o tipo de vitamina $\mathrm{D}$ adicionada e as possíveis perdas no armazenamento. Vale salientar que o controle laboratorial existente no programa refere-se apenas à quantidade de ferro e vitamina A presentes no leite fortificado.

Segundo as DRI (dietary reference intakes ingestão diária recomendada) 47 , a quantidade necessária para manter as concentrações séricas de vitamina $\mathrm{D}$ aceitáveis (20ng/mL) é de $10 \mu \mathrm{g} /$ dia (400UI), porém alguns autores apontam que, a cada 100UI $(2,5 \mu \mathrm{g})$ ingeridos por dia, aumentam em $0,7 \mathrm{ng} / \mathrm{mL}$ a concentração dessa vitamina 37. Considerando a ingestão alimentar média observada de $3 \mu \mathrm{g} / \mathrm{dia}$, incluindo o leite fortificado, pode-se dizer que o consumo está muito aquém do valor mínimo recomendado. Extrapolando esses dados, caso a criança consumisse o volume de leite recomendado para um dia 500 $\mathrm{mL}$ ( $\sim 3$ porções), que atende $50 \%$ da EAR, isso representaria um adicional de $5 \mu \mathrm{g}$ no consumo alimentar da criança.

A ausência de marcador de inflamação e o fato da amostra estudada não representar todo o universo de crianças atendidas pelo programa no estado, pois o estudo foi conduzido com crianças atendidas no centro da cidade de São Paulo, 
podem ser consideradas como limitações do estudo. No entanto, vale esclarecer que as crianças que tinham alguma doença crônica ou que no dia da coleta, estavam em uso de medicamento anti-inflamatório ou apresentavam febre não foram incluídas na análise.

Apesar do estudo ter sido conduzido com uma amostra de conveniência é possível aventar a hipótese de que caso o alimento fortificado não seja direcionado exclusivamente para a criança beneficiária, mas, sim, distribuído para outros membros da família, o programa de suplemnetação alimentar em outros grupos de beneficiários não terá seus objetivos alcançados de forma efetiva. O desconhecimento das qualidades especiais do leite fortificado, tanto pelos representantes das entidades distribuidoras quanto pelas mães, contribui para que a criança-alvo não seja privilegiada no consumo do leite fortificado dentro da família. Situação semelhante foi também identificada em estudo realizado com beneficiários do programa no Município de Santo André, São Paulo 66. Contudo, é importante destacar a importância de se avaliar diferentes hábitos de vida entre crianças e famílias da capital São Paulo com aquelas do interior e litoral, onde hábitos de vida podem influenciar o estado nutricional das vitaminas estudadas.

Como conclusão, a situação nutricional encontrada neste estudo para as vitaminas A e D indicam que as estratégias de ações de intervenção devem ser revisadas. Para tanto, sugere-se melhor direcionamento, por parte dos gestores do programa, no sentido de orientar as famílias quanto às propriedades nutricionais do leite fortificado e da importância da forma correta de sua utilização, na orientação da prática de alimentação saudável e exposição solar adequada na tentativa de melhorar o estado nutricional das vitaminas A e D nessa população.

\section{Resumen}

Se evaluaron las concentraciones séricas de vitaminas A y D y factores asociados en niños que se benefician del programa de distribución de leche fortificada. Se utilizaron múltiples modelos de regresión lineal, con una selección jerárquica de las variables independientes (estatus sociodemográfico, salud, alimentación, lactancia materna, consumo de leche fortificada, exposición al sol, medidas antropométricas, retinol y calcidiol séricos). Para la insuficiencia y deficiencia de vitamina A y vitamina $D$, se adoptaron concentraciones séricas $<1,05 \mu \mathrm{mol} / \mathrm{L},<0,70 \mu \mathrm{mol} / \mathrm{L},<30 \mathrm{ng} / \mathrm{mL},<20 \mathrm{ng} / \mathrm{mL}$, respectivamente. La inadecuación del consumo de alimentos para vitamina A y vitamina $D$ fue de un $40 \%$ y 100\%, respectivamente. La prevalencia de insuficiencia y la deficiencia de vitamina A y vitamina $D$ fue de un $19 \%, 6 \%, 82 \%$ y 58\%, respectivamente. Los factores asociados más pequeños de vitamina A sérica fueron: lactancia exclusiva < 120 días, ausencia de empleo de la madre, combinada con una baja educación materna y menor vitamina $D$ sérica. Para la vitamina $D$ fueron: menor exposición al sol y menor vitamina A sérica. Las acciones de educación nutricional son necesarias para mejorar la situación nutricional de estos niños.

Alimentos Fortificados; Avitaminosis; Alimentación Suplementaria; Estado Nutricional; Programas de Gobierno

\section{Colaboradores}

A. Y. Kurihayashi realizou a coleta dos dados, organização e análise dos resultados e redação do artigo. R. A. Augusto contribuiu na análise estatística, redação do artigo, interpretação dos dados e revisão crítica do conteúdo. F. M. D. Escaldelai colaborou na coleta dos dados e revisão crítica do conteúdo. L. A. Martini participou da concepção do estudo, análise dos dados, redação do artigo, revisão crítica do conteúdo e aprovação da versão final do manuscrito.

\section{Agradecimentos}

À Capes, pela bolsa de estudos concedida a A. Y. Kurihayashi, e ao Núcleo de Apoio à Pesquisas em Alimentos e Nutrição, Universidade de São Paulo (NAPANUSP). 


\section{Referências}

1. Secretaria de Atenção à Saúde, Ministério da Saúde. Política de Alimentação e Nutrição - PNAN. Brasília: Ministério da Saúde; 2012.

2. Holick MF, Chen TC. Vitamin D deficiency: a worldwide problem with health consequences. Am J Clin Nutr 2008; 87:1080S-6S.

3. Holick MF. Vitamin D deficiency. N Engl J Med 2007; 357:266-81.

4. Lips P. Worldwide status of vitamin D nutrition. J Steroid Biochem Mol Biol 2010; 121:297-300.

5. Pearce SH, Cheetham TD. Diagnosis and management of vitamin D deficiency. BMJ 2010; 340:b5664.

6. World Health Organization. Global prevalence of vitamin A deficiency in populations at risk 19952005: WHO global database on vitamin A deficiency. Geneva: World Health Organization; 2009.

7. Ministério da Saúde. Pesquisa Nacional de Demografia e Saúde da Criança e da Mulher - PNDS 2006: Dimensões do processo reprodutivo e da saúde da criança. Brasília: Ministério da Saúde; 2006. (Série G. Estatística e Informação em Saúde).

8. Lourenço BH, Qi L, Willett WC, Cardoso MA; ACTION Study Team. FTO genotype, vitamin D status, and weight gain during childhood. Diabetes $2014 ; 63: 808-14$.

9. Raimundo FV, Bueno AL, Moulin CC, Czepielewski MA. Variação sazonal de níveis de 25-hidroxivitamina D sérica e ingestão dietética de vitamina D em crianças e adolescentes com baixa estatura. Rev HCPA \& Fac Med Univ Fed Rio Gd do Sul 2010; 30:209-13.

10. Institute of Medicine. Dietary reference intakes for calcium, phosphorus, magnesium, vitamine D and fluoride. Washington DC: National Academy Press; 1997.

11. Ramalho A, Padilha P, Saunders C. Análise crítica de estudos brasileiros sobre deficiência de vitamina A no grupo materno-infantil. Rev Paul Pediatr 2008; 26:392-9.

12. Cribb VL, Northstone K, Hopkins D, Emmett PM. Sources of vitamin A in the diets of pre-school children in the Avon Longitudinal Study of Parents and Children (ALSPAC). Nutrients 2013; 5:1609-21.

13. Underwood BA, Arthur P. The contribution of vitamin A to public health. FASEB J 1996; 10:1040-8.

14. Mason JB, Lotfi M, Dalmiya N, Sethuraman K, Deitchler M, Geibel S, et al. The Micronutrient Report: current progress and trends in the control of vitamin a, iodine, and iron deficiences. Ottawa: International Development Research Centre/Micronutrient Initiative; 2001.

15. Miller M, Humphrey J, Johnson E, Marinda E, Brookmeyer R, Katz J. Why do children become vitamin A deficient? J Nutr 2002; 132:S2867-80.

16. Jiang JX, Lin LM, Lian GL, Greiner T. Vitamin A deficiency and child feeding in Beijing and Cuizhou, China. World J Pediatr 2008; 4:20-5.

17. Martins MC, Santos LMP, Assis AMO. Prevalência da hipovitaminose A em pré-escolares no Estado de Sergipe, 1998. Rev Saúde Pública 2004; 38: 537-42.
18. Oliveira JS, Lira PIC, Osório MM, Sequeira LAS, Costa EC, Gonçalves FCLSP, et al. Anemia, hipovitaminose A e insegurança alimentar em crianças de municípios de Baixo Índice de Desenvolvimento Humano do Nordeste do Brasil. Rev Bras Epidemiol 2010; 13:651-64.

19. Queiroz D, Paiva AZ, Pedraza DF, Cunha MAL, Esteves GH, Luna JG, et al. Deficiência de vitamina A e fatores associados em crianças de áreas urbanas. Rev Saúde Pública 2013; 47:248-56.

20. Miglioli TC, Fonseca VM, Gomes Junior SC, Lira PIC, Batista-Filho M. Deficiência de vitamina A em mães e filhos no Estado de Pernambuco. Ciênc Saúde Coletiva 2013; 18:1427-40.

21. Ferraz IS, Daneluzzi JC, Vannucchi H. Vitamin A deficiency in children aged 6 to 24 months in Sao Paulo State, Brazil. Nutr Res 2000; 20:757-68.

22. Midyat L, Kurugöl NZ, Aksit S, Tanrıverdi M, Yağcı RV. Dietary vitamin A intake and serum retinol concentrations of preschool children from different socio-economical levels in Izmir, Turkey. Acta Paediatr 2011; 100:e24-7.

23. Tansuğ N, Polat M, Çeşme S, Taneli F, Gözmen S, Tokuşoğlu O, et al. Vitamin A status of healthy children in Manisa, Turkey. Nutr J 2010; 9:34.

24. Ramalho RA, Flores H, Accioly E, Saunders C. Associação entre deficiência de vitamina A e situação sociodemográfica de mães e recém-nascidos. Rev Assoc Med Bras 2006; 52:170-5.

25. Norris J. Can the sunshine vitamin shed light on type 1diabetes? Lancet 2001; 358:1476-8.

26. Nicolaidou P, Kakourou T, Papadopoulou P, Kavadias G, Dimitriou E, Georgouli H, et al. Low vitamin D status in preschool children in Greece. Nutr Res 2006; 26:620-5.

27. Cashman KD. Vitamin D in childhood and adolescence. Postgrad Med J 2007; 83:230-5.

28. Scientific Advisory Committee on Nutrition. Update on vitamin D: position statement by the Scientific Advisory Committee on Nutrition. London: The Stationery Office; 2007.

29. Greer FR. Defining vitamin D deficiency in children: beyond 25-OH vitamin D serum concentrations. Pediatrics 2009; 124:1471-3.

30. Wang TJ, Zhang F, Richards JB, Kestenbaum B, van Meurs JB, Berry D, et al. Common genetic determinants of vitamin D insufficiency: a genome-wide association study. Lancet 2010; 376:180-8.

31. Misra M, Pacaud D, Petryk A, Collett-Solberg PF, Kappy M; Drug and Therapeutics Committee of the Lawson Wilkins Pediatric Endocrine Society. Vitamin D deficiency in children and its management: review of current knowledge and recommendations. Pediatrics 2008; 122:398-417.

32. Heaney RP. Functional indices of vitamin D status and ramifications of vitamin D deficiency. Ame J Clin Nutr 2004; 80(6 Suppl):1706S-9S.

33. Wang TJ, Pencina MJ, Booth SL, Jacques PF, Ingelsson E, Lanier K, et al. Vitamin D deficiency and risk of cardiovascular disease. Circulation 2008; 117:503-11. 
34. Reis JP, von Muhlen D, Miller 3rd ER, Michos ED, Appel LJ. Vitamin D status and cardiometabolic risk factors in the United States adolescent population. Pediatrics 2009; 124:e371-9.

35. Hypponen E, Laara E, Reunanen A, Jarvelin MR, Virtanen SM. Intake of vitamin D and risk of type 1 diabetes: a birth-cohort study. Lancet 2001; 358:1500-3.

36. Chiu KC, Chu A, Go VL, Saad MF. Hypovitaminosis $\mathrm{D}$ is associated with insulin resistance and beta cell dysfunction. Am J Clin Nutr 2004; 79:820-5.

37. Mitri J, Muraru MD, Pittas AG. Vitamin D and type 2 diabetes: a systematic review. Eur J Clin Nutr 2011; 65:1005-15.

38. Trump DL, Deeb KK, Johnson CS. Vitamin D: considerations in the continued development as an agent for cancer prevention and therapy. Cancer J 2010; 16:1-9.

39. Willer CJ, Dyment DA, Sadovnick AD, Rothwell PM, Murray TJ, Ebers GC. Timing of birth and risk of multiple sclerosis: population based study. BMJ 2005; 330:120.

40. Absoud M,Cummins C, Lim MJ,WassmerE, Shaw N. Prevalence and predictors of vitamin D insufficiency in children: a Great Britain population based study. PLoS One 2011; 6:e22179.

41. São Paulo. Decreto no 45.014 , de 28 de junho de 2000. Altera o Decreto no 44.569, de 22 de dezembro de 1999, que instituiu o Projeto Estadual do Leite "Vivaleite". Diário Oficial do Estado de São Paulo 2000; 28 jun.

42. Secretaria de Agricultura e Abastecimento do Estado de São Paulo. Resolução da Secretaria de Agricultura e Abastecimento do Estado de São Paulo - SAA 24, de 1o de agosto de 2000. Regulamenta o Projeto Estadual do Leite "Vivaleite", estabelecendo as regras de credenciamento e de participação de entidades da sociedade civil e de Prefeituras Municipais na sua execução. Diário Oficial do Estado de São Paulo 2000; 1 ago.

43. Sá ACE, Szarfarc SC. Prevalência de anemia em crianças antes e durante participação em programa de fortificação alimentar com ferro. Nutrire Rev Soc Bras Aliment Nutr 2009; 34:115-26.

44. Augusto RA, Souza JMP. Efetividade de programa de suplementação alimentar no ganho ponderal de crianças. Rev Saúde Pública 2010; 44:793-801.

45. Grant WB, Holick MF. Benefits and requirements of vitamin D for optimal health: a review. Altern Med Rev 2005; 10:94-111.

46. Institute of Medicine. Dietary reference intakes: applications in dietary planning. Washington DC: National Academies Press; 2003.

47. Institute of Medicine. Dietary reference intakes for vitamin $\mathrm{A}$, vitamin $\mathrm{K}$, arsenic, boron, chromium, copper, iodine, iron, manganese, molybdenum, nickel, silicon, vanadium, and zinc. Washington DC: National Academies Press; 2001.

48. Institute of Medicine. Dietary reference intakes for calcium and vitamin D. Washington DC: National Academies Press; 2011.

49. Lohmann TG. Anthropometric standardization reference manual. Champaign: Human Kinetics; 1988.
50. World Health Organization. World Health Organization releases new child growth standards. Geneva: World Health Organization; 2006.

51. De Onis M, Onyango AW, Borghi E, Siyam A, Nishida C, Siekmann J. Development of a WHO growth reference for school-aged children and adolescents. Bull World Health Organ 2007; 85:660-7.

52. World Health Organization. Indicators for assessing vitamin A deficiency and their application in monitoring and evaluating intervention programmes. Geneva: World Health Organization; 1996.

53. Victora CG, Aquino EM, Leal MC, Monteiro CA, Barros FC, Szwarcwald CL. Maternal and child health in Brazil: progress and challenges. Lancet 2011; 377:1863-76.

54. United Nations Children's Fund. Goals for children and development in the 1990s. World Summit for children. New York: United Nations Children's Fund; 1990.

55. Hossein-Nezhad A, Holick MF. Vitamin d for health: a global perspective. Mayo Clin Proc 2013; 88:720-55.

56. Flores M, Macias N, Lozada A, Sánchez LM, Díaz E, Barquera S. Serum 25-hydroxyvitamin D levels among Mexican children ages $2 \mathrm{y}$ to $12 \mathrm{y}$ : a national survey. Nutrition 2013; 29:802-4.

57. Díaz JR, De Las Cagigas A, Rodríguez R. Micronutrient deficiencies in developing and affluent countries. Eur J Clin Nutr 2003; 57 Suppl 1:S70-2.

58. Frost MB, Forste R, Haas DW. Maternal education and child nutritional status in Bolivia: finding the links. Soc Sci Med 2005; 60:395-407.

59. Burchi F. Child nutrition in Mozambique in 2003: the role of mother's schooling and nutrition knowledge. Econ Hum Biol 2010; 8:331-45.

60. Abuya BA, Ciera J, Kimani-Murage E. Effect of mother's education on child's nutritional status in the slums of Nairobi. BMC Pediatr 2012; 12:80.

61. Matsuoka LY, Ide L, Wortsman J, MacLaughlin JA, Holick MF. Sunscreens suppress cutaneous vitamin D3 synthesis. J Clin Endocrinol Metab 1987; 64:1165-8.

62. Clemens TL, Adams JS, Henderson SL, Holick MF. Increased skin pigment reduces the capacity of skin to synthesis vitamin D3. Lancet 1982; 1:74-6.

63. Bischoff-Ferrari HA, Giovannucci E, Willett WC, Dietrich T, Dawson-Hughes B. Estimation of optimal serum concentrations of 25-hydroxyvitamin D for multiple health outcomes. Am J Clin Nutr 2006; 84:18-28.

64. Holick MF, Binkley NC, Bischoff-Ferrari HA, Gordon CM, Hanley DA, Heaney RP, et al. Evaluation, treatment, and prevention of vitamin $\mathrm{D}$ deficiency: an Endocrine Society clinical practice guideline. J Clin Endocrinol Metab 2011; 96:1911-30.

65 . Vieth R, The urgent need to reconsider recommendations for vitamin d nutrition intake. Am J Clin Nutr 2007; 85:649-50.

66. Viski MM, Augusto RA, Szarfarc SC. O projeto Vivaleite no município de Santo André. Nutrire Rev Soc Bras Aliment Nutr 2006; 31:15-26.

Recebido em 27/Mai/2014

Versão final reapresentada em 20/Out/2014

Aprovado em 31/Out/2014 